Faculty of Veterinary Medicine, AlBaath University, Syria

\title{
ISOLATION CORYNEBACTERIUM.SPP AND OTHER BACTERIA CAUSING SUPERFICIAL ABSCESS IN AWASSI SHEEP IN THE EASTERN OF AREA SYRIA \\ (With 6 Tables)
}

\section{By}

\section{S. ALHWALA and I. RIFAI}

(Received at 16/5/2011)

\section{عزل الوتديات وغيرها من المسبيات الجرثومية للخراجات السطحية عند أغنام العواس في المنطقة الشرقية المبرية من سوريا$$
\text { سليمان الحوالة ، إبراهيم الرفاعي }
$$

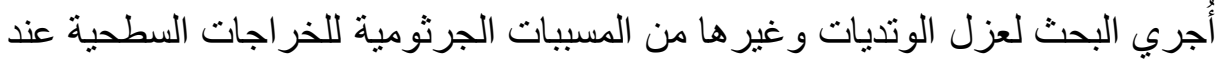

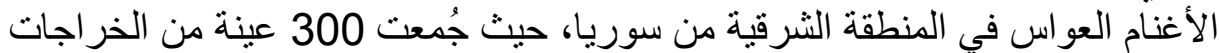

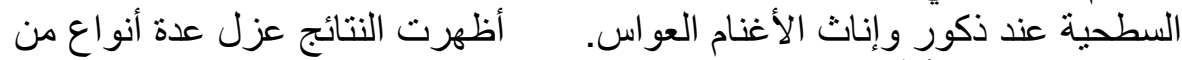
الجر اثثم وهي الََتَنَيَّات

و العنقوديات Streptococcus و والعقديات و والمُكَيّر ات و والإشريكية القولونية Micrococcus Pseudomonas ، Bacillus spp.

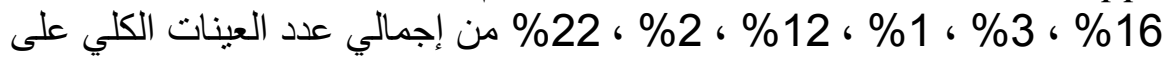

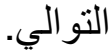

كلمات مفتاحية: الخراجات ، أغنام العواس ، الوتديات ، العنقوديات ، الزورائف ، العقديات ، الاشريكية القولونبية.

\section{SUMMARY}

This study was performed to isolate Corynebacterium.spp and other bacteria causing superficial abscesses in Awassi sheep in the eastern area of Syria. 300 Samples were collected from superficial abscesses in male 
and female Awassi sheep. Results showed that there were many kinds of bacteria as Corynebacterium, Arcanobacterium pyogenes, Staphylococcus, Streptococcus, Micrococcs, Escherichia coli, Pseudomonas, Enterobacter and Klebsiella, Bacillus.spp and their percentages were respectively $\% 32$ ، \%14 ، \%39 ، \%15 ، \%16 ، \%3 ، $\% 1$ ، \%12 ، \%2 ، \%22 from the total samples.

Key words: Sheep, abscess, Corynebacterium, Pseudomonas, E.coli, Staph, Strept.

\section{INTRODUCTION}

\section{مُقَدَّمَسة}

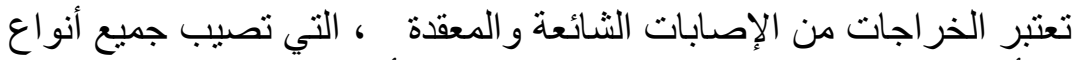

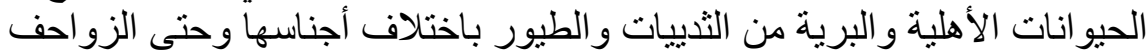

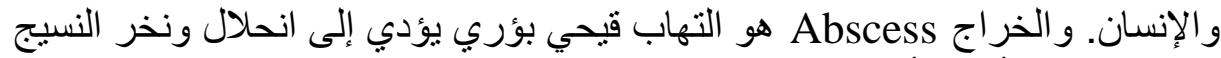

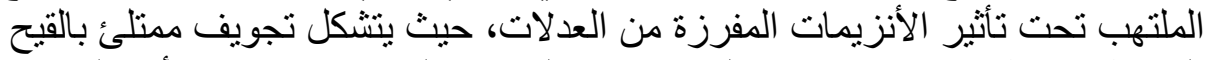

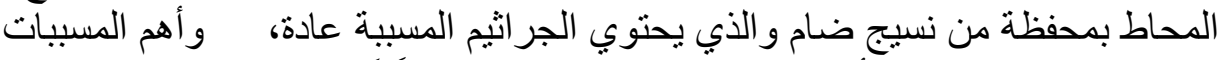
الوَتَدَيَّات Corynebacterium

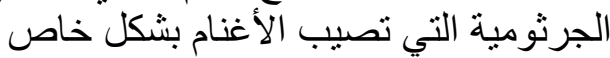
(Babiker and El Sanousi, 2004) (Tadayon et al., 1980; Corynebacterium pseudotuberculosis Walker, 1996; Glenn and Karen, 2005; Paton, 2005; Goldman and

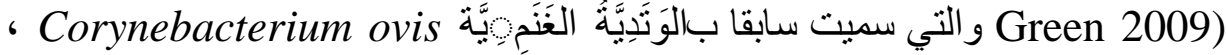
Caseous

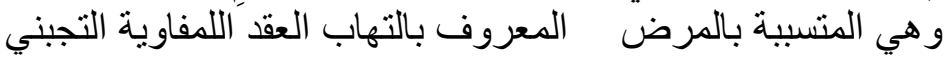
(Lloyd, 1998; Hirsh and Zee1999; Aitken, (CL) Lymphadenitis (2007، حيث ذكر أن نصف الأغنام المذبوحة في المسالخ في أكثر من 400 فطيع

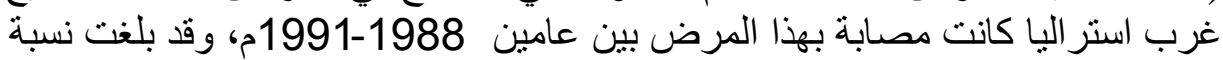
انتشاره عام 1995م في قطعان الأغنام في استر اليا 20\% 2005 (Paton, 2005) وكذلك (Gerlach et al., 1994 ; Hirsh and Arcanobacterium pyogenes Zee1999; Lavin et al 2004; Jost and Billington 2005)

Corynebacterium pyogenes تصنف ضمن جنس الوتديات باسم الوتدية المقيحة

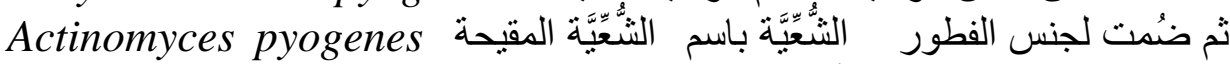
(Quinn et al., 1999)

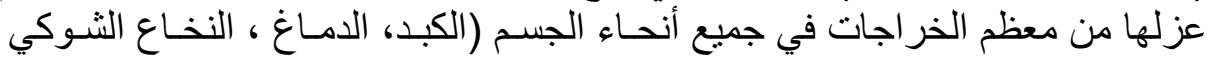

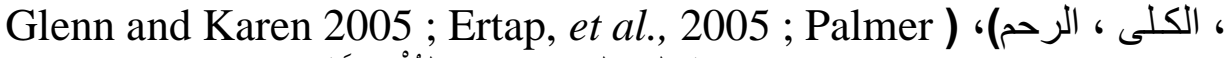
Staphylococcus بالإضافـة إلى المكورات العُنْوَدِيَّة 1999 Staphylococcus aureus ومن أهم أنواعها 
Staphylococcus والمكورات العُنْقوديَّة البشروية (El Sanousi et al., 1989) (Tadayon et al., 1980; Carter et al., 1995; Glenn and epidermidis Streptococcus ومن أهمها المكور ات

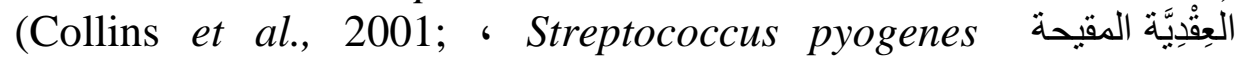

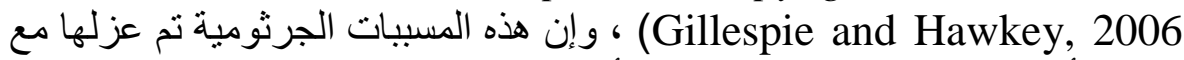

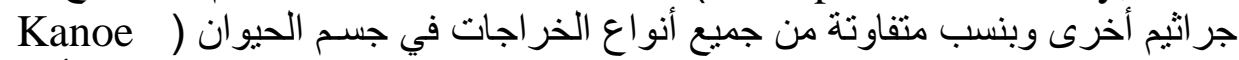
طرق الجر 2006 طرق تلوث البيئة المحيطة بهذه المسببات الجرثومية هو انفجار الخراجات السطحية أو الإفرازات و السيلانـات (Tadayon et al., 1980; Glenn and Karen, 2005)

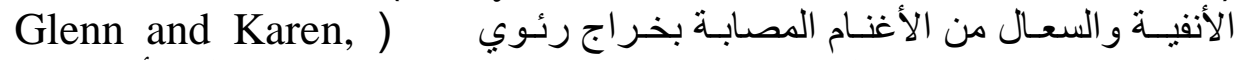
2005)، حيث تتمكن هذه الجر اثيم من البقاء حية بوجود المواد الثئ العضوية لعدة أثنهر

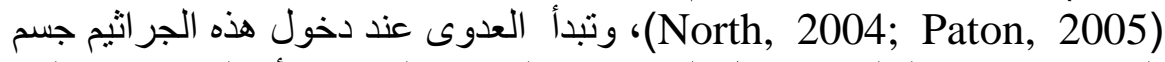

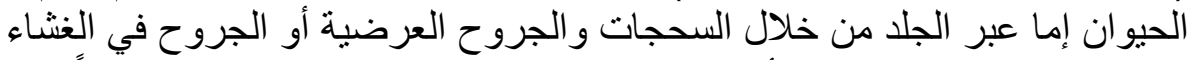

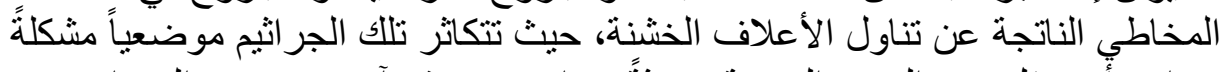

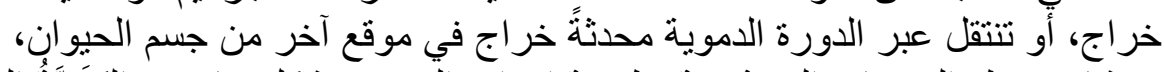

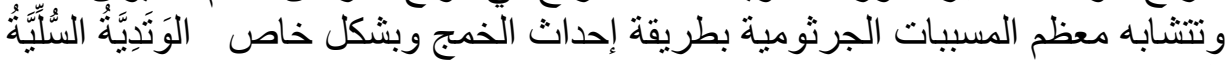

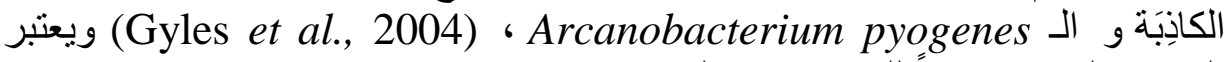

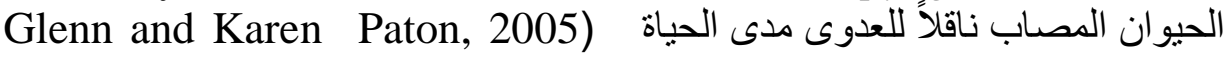

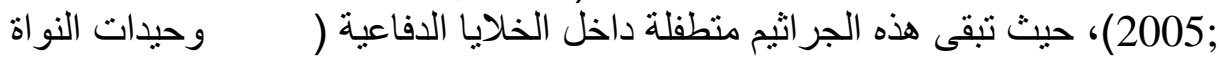

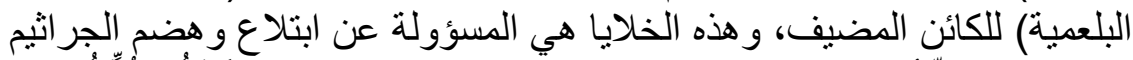

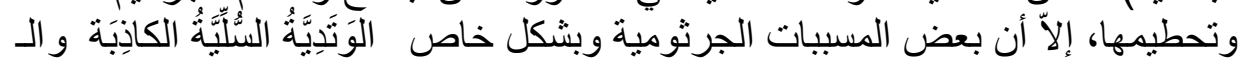
Arcanobacterium pyogenes

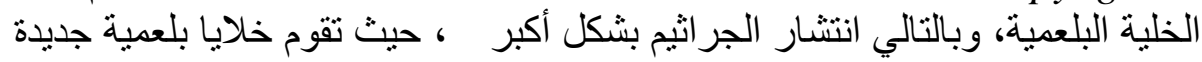

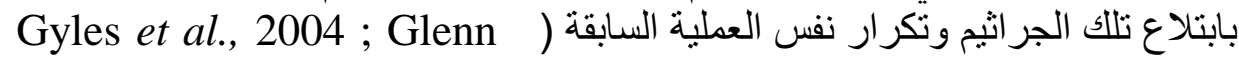
. and Karen, 2005

تختلف أعر اض الخراجات ح سب مكان توضعها، فإذا كان الخر اج مفتوح

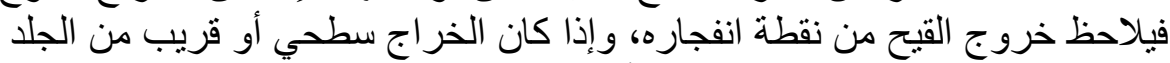

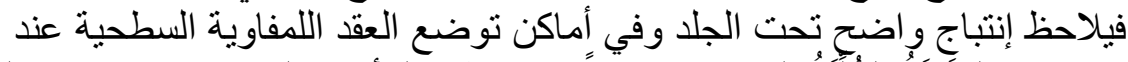

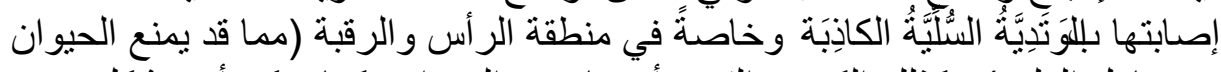

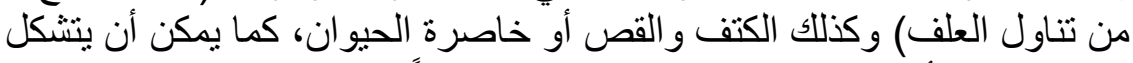

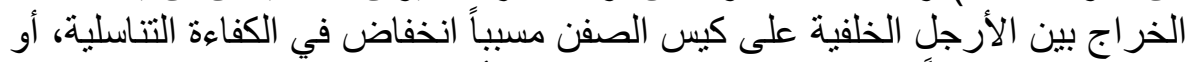

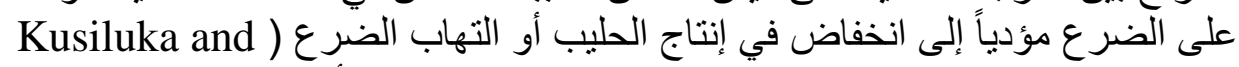

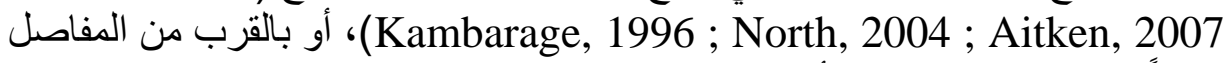

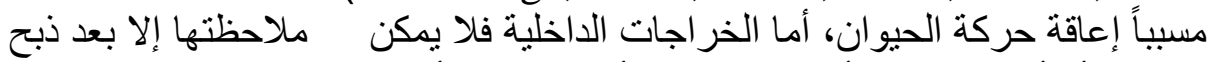

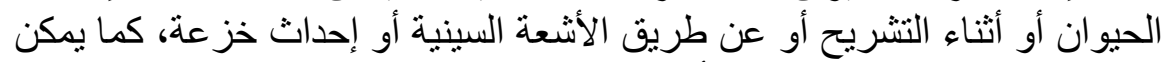

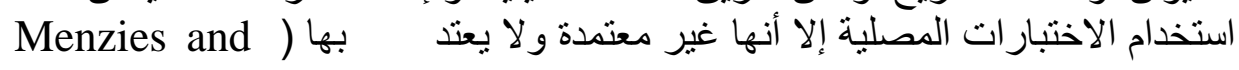




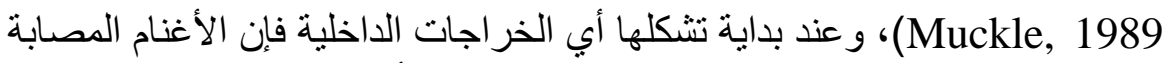

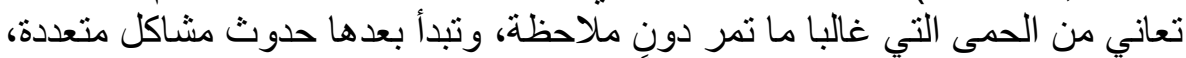

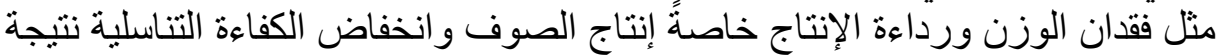

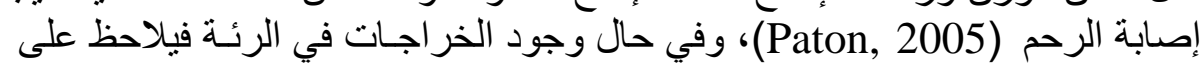
الحيوان ضائقة تنفسية وسعال مزمن (

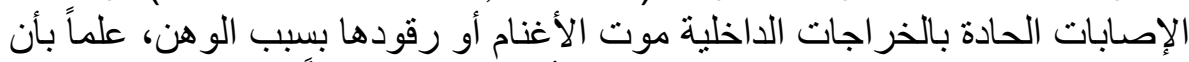

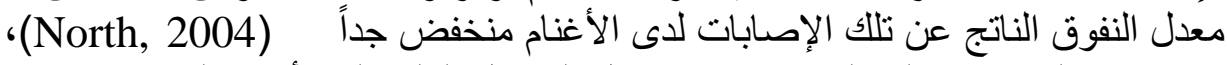

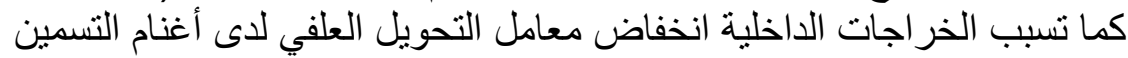

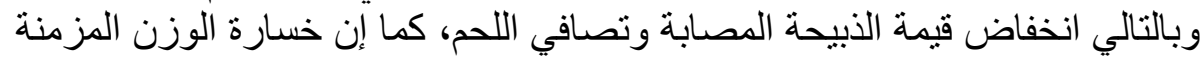

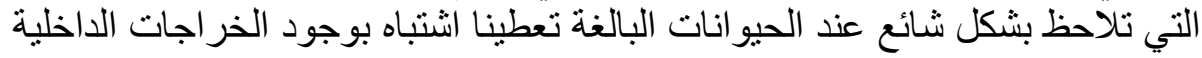

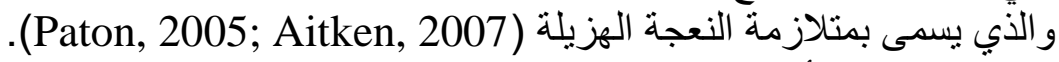

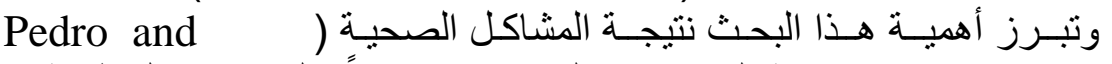

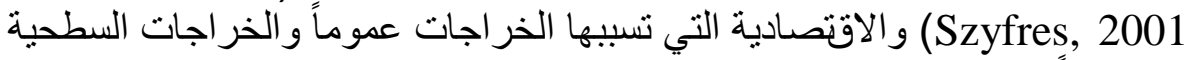
خصوصاً من حيث :

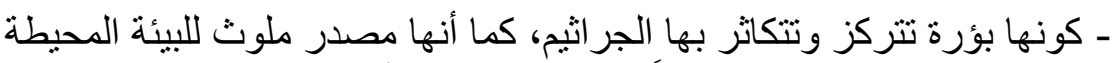

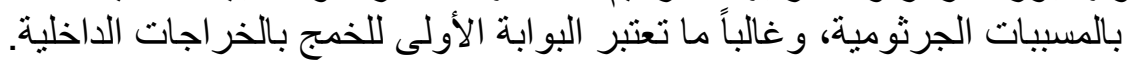

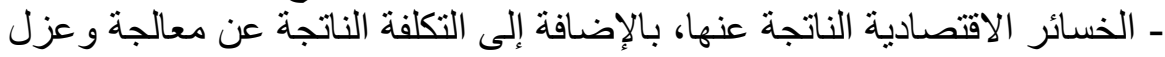
الحيو انات المصابة.

\section{أهدف البحث}

ا. ـ التشخيص الحقلي للخر اجات السطحية عند الأغنام العو اس في المنطقة الثرقية r. عزل المسببات الجرثومية لهذه الإصابات وتصنيفها.

\section{المواد وطر ائق العمل \\ MATERIALS and METHODS}

'أُ العينات : 300 عينة من ذكور و إناث الأغنام العواس في المنطقة الثرقية من سوريا 


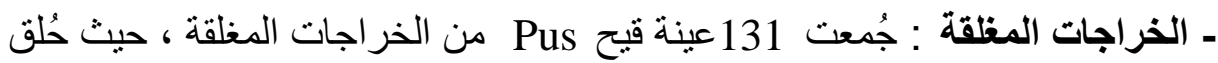
الثعر وتم شق الجلد بمشرط معقم بعد تعقيم مكان الثق، وُوسحب القيح بمحقن معقم.

ـ الخراجات المفتوحة : جُمعت 169 عينة من الخر اجات المفتوحة باستخدام ماسحات

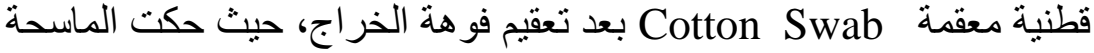

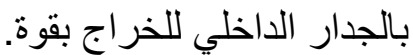

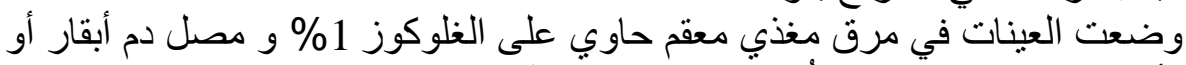

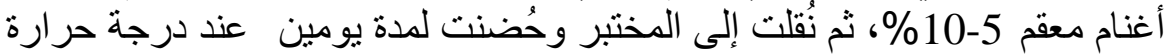

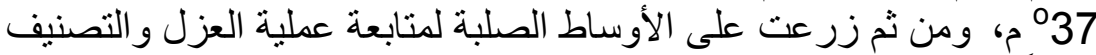
لاحقاً.

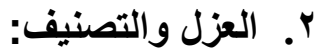

$$
\text { 201 زر: العزل : }
$$

- وسط آجار الماكونكي MacConkey Agar Medium لزر اعة و تمييز عائلة الجر اثثم المعوية Enterobacteriaceae وبعض الجر الثيمي السلبية الغرام ودر اسة الخو اص الثكلية للمستعمر ات الجرثومية.

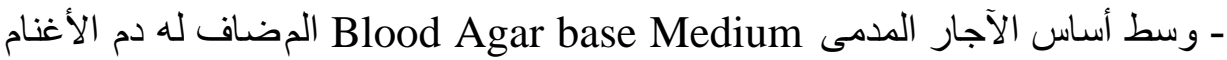

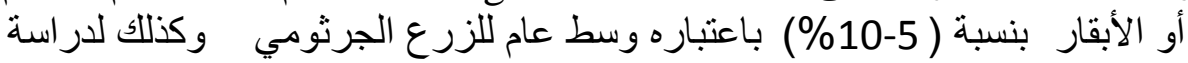

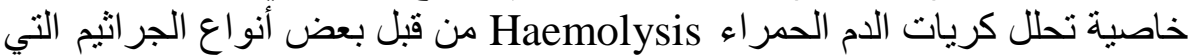

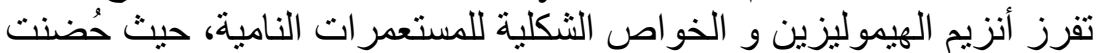

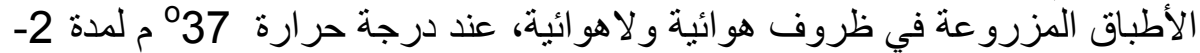

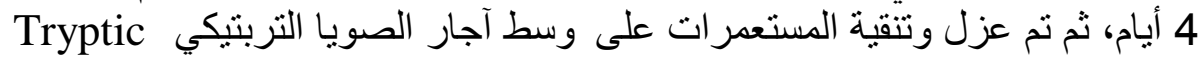
Soy Agar

202 20201. التصنيف الأولي: بودئ

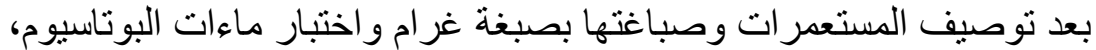

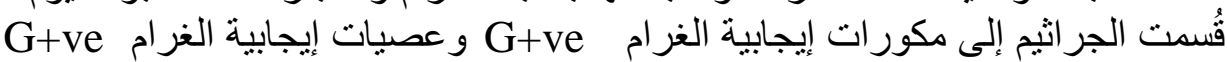

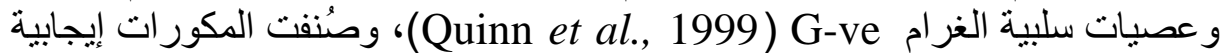

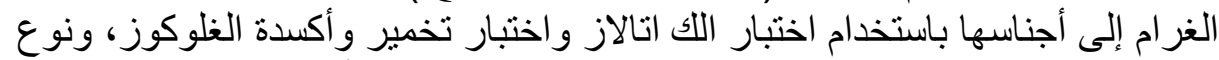

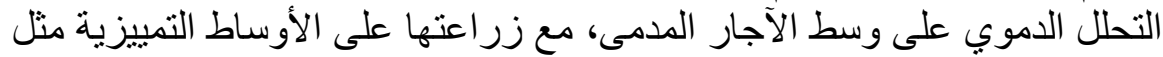

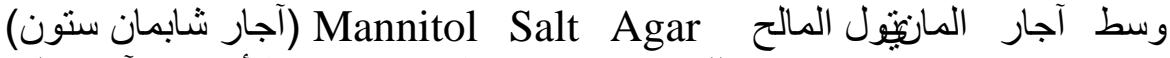
للعنقوديات، ووسط باركر (وسط أساس الآجار المدمى (Chapman Stone Agar) 
بالأزيد وبنفسجية الكريستال) (Crystal Violet-Azide Blood Agar) للعقديات، أما الأاسات

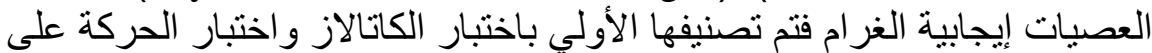

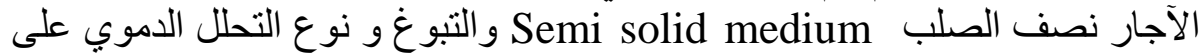

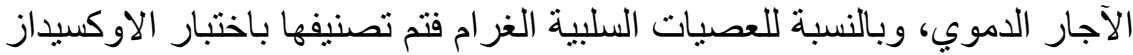

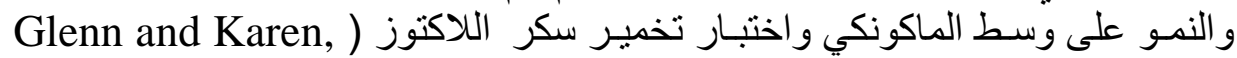
.(2005

\section{2. التصنيف بالاختبارات الكيميائية الحيوية : بالنية}

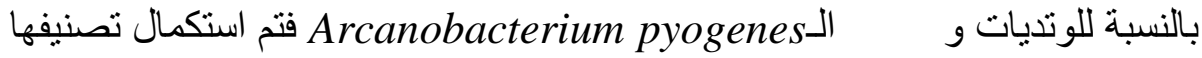

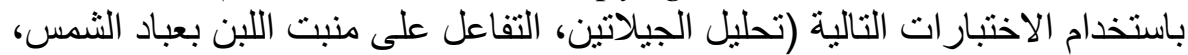
إرجاع النترات، تحلل اليوريا، أكسدة السكاكر) (Quinn et al., 1999).

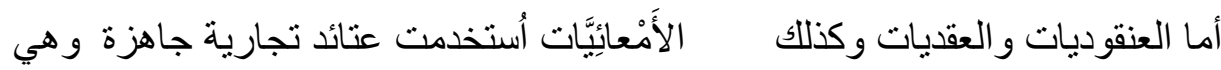

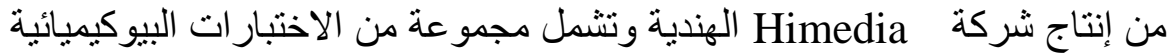

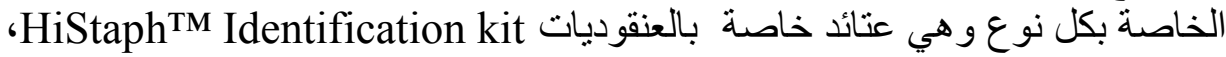
و ونائد خاصة بالعقديات بالأمعائيات

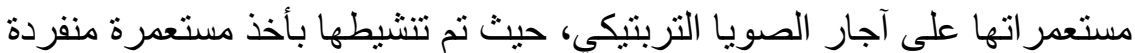

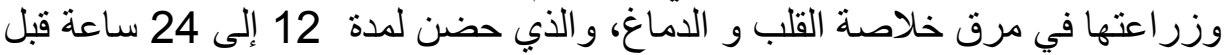

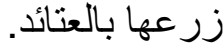

\section{RESULTS}

\section{النتائسجة}

أُجريت هذه الدراسة على 127 قطيع من أغنام العواس في المنطقة الثرقية

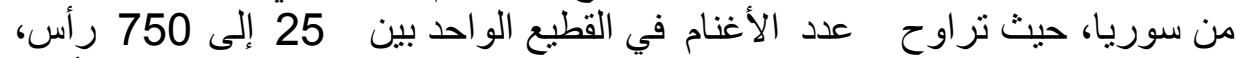

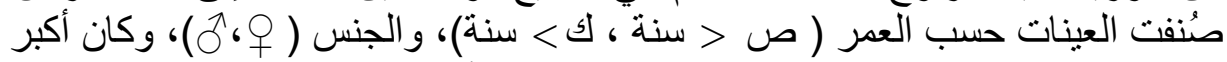

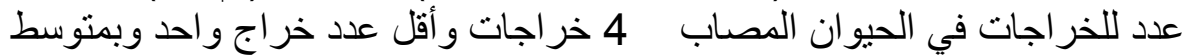
(1,39) خر اج، ويوضح الجدول رقم 1 (1) نسبة الأغنام المصابة بالخر اجات الخات السطحية إلى عدد الأغنام الكلي في القطيع الواحد. 
Assiut Vet. Med. J. Vol. 57 No. 130 July 2011

الجدول رقم (1): نسبة الذراجات و الاغنام المصابة إلى عدد أغنام كل قطيع على حدة

\begin{tabular}{|c|c|c|}
\hline نسبة الخ راجات في & نسبة الأغنام المصابة في & \\
\hline $2.57 \%$ & $1.95 \%$ & المتوسط الحسابي \\
\hline $12.17 \% *$ & $* 8.7 \%$ & اعلى نسبة \\
\hline $0.18 \%$ & $0.18 \%$ & ادنى نسبة \\
\hline
\end{tabular}

ت رعى هذه الاغنام في منطقة حاوبة على نباتات شدوكية و بقايا

* النباتات المتخثبة

ويوضح الجدول رقم ( 2) عدد الأغنام المصابة بالنسبة إلى مجموع الأغنام الكلي في جميع قطعان الدراسة.

الجدول رقم (2): عدد ونسبة كل من الذراجات والأغنام المصابة إلى مجموع الأغنام في كل قطعان الدرا سة

\begin{tabular}{|c|c|c|c|c|c|}
\hline نسبة الذراجات & نسبة الأغنام المصابة & العدد الكلي للقطعان & عدد الذراجات & عدد المصابة & 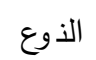 \\
\hline $1.66 \%$ & $1.36 \%$ & 1983 & 33 & 27 & ك \\
\hline $0.13 \%$ & $0.05 \%$ & 7450 & 10 & 4 & مَ ص \\
\hline $1.48 \%$ & $1.27 \%$ & 16923 & 250 & 215 & s \\
\hline $0.09 \%$ & $0.04 \%$ & 7512 & 7 & 3 & ص \\
\hline $0.89 \%$ & $0.74 \%$ & 33868 & 300 & 249 & \\
\hline
\end{tabular}

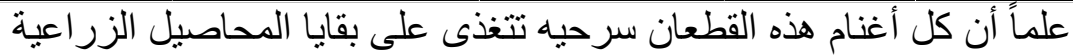

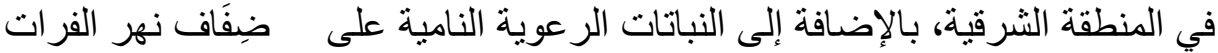

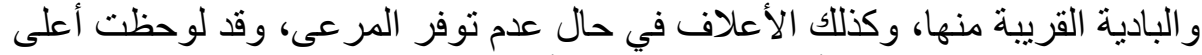

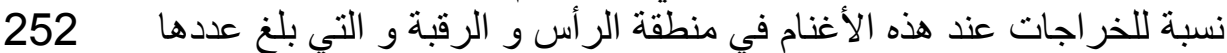

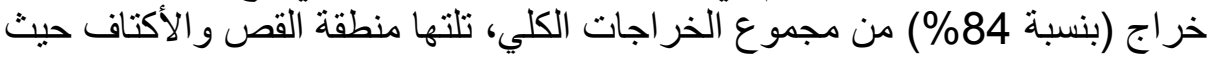

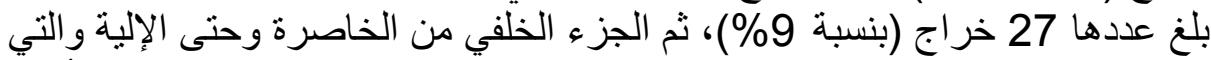

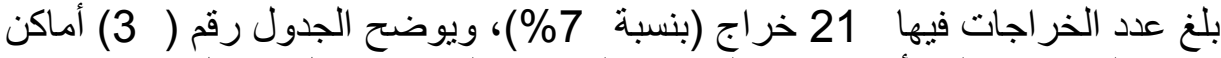
توزع الخر اجات التي أخذت منها العينات على جسم الحيو الحئ ان بشكل مفصل. 
Assiut Vet. Med. J. Vol. 57 No. 130 July 2011

الجدول رقم (3): أماكن توزع الذراجات الني أخذة منها العينات بشكل مفصل

\begin{tabular}{|c|c|c|c|c|c|c|}
\hline المنطقة & | النسبة المدٔوية | & | المجموع| & النسبة المئوية لكل & النسبة العامة & | عدد & موقع الذراجات \\
\hline \multirow{4}{*}{ الـ أس و الرقبة } & \multirow{4}{*}{$84 \%$} & \multirow{4}{*}{252} & $14.7 \%$ & $12.3 \%$ & 37 & وجهي (امام العين) \\
\hline & & & $42.5 \%$ & $35.7 \%$ & 107 & فكي \\
\hline & & & $25.8 \%$ & $21.7 \%$ & 65 & حول الاذن \\
\hline & & & $17.1 \%$ & $14.3 \%$ & 43 & العنق (حنجري عنقي) الألث \\
\hline \multirow{2}{*}{ القص و الكتّ } & \multirow{2}{*}{$9 \%$} & \multirow{2}{*}{27} & $55.6 \%$ & $5.0 \%$ & 15 & القص \\
\hline & & & $44.4 \%$ & $4.0 \%$ & 12 & الكتق \\
\hline \multirow[t]{2}{*}{ الجزء الخلفي } & \multirow[t]{2}{*}{$7 \%$} & \multirow[t]{2}{*}{21} & $66.7 \%$ & $4.7 \%$ & 14 & 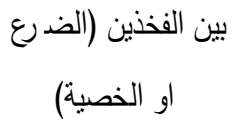 \\
\hline & & & $33.3 \%$ & $2.3 \%$ & 7 & القوائم (بين الظلفين) \\
\hline & $100 \%$ & 300 & $300 \%$ & $100 \%$ & 300 & المجدوع الكلي \\
\hline
\end{tabular}

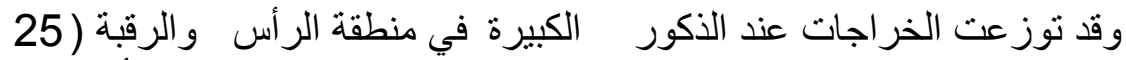

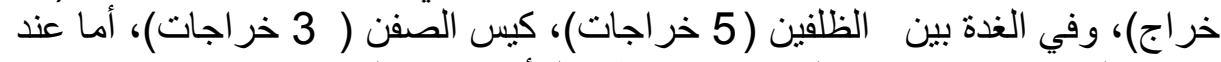

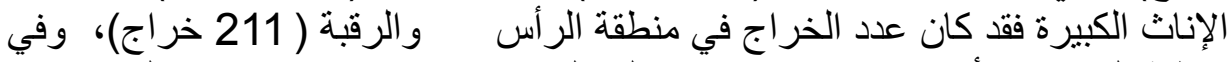

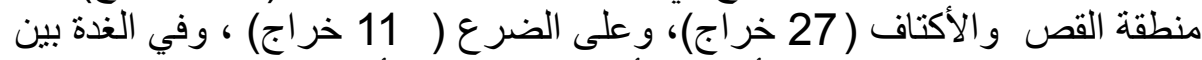

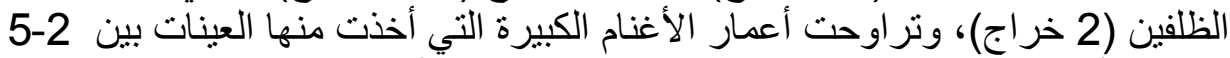

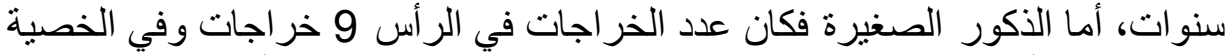

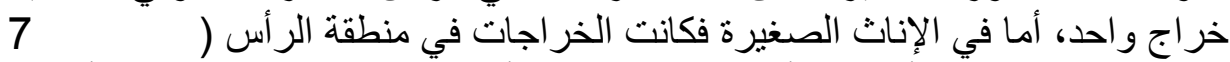

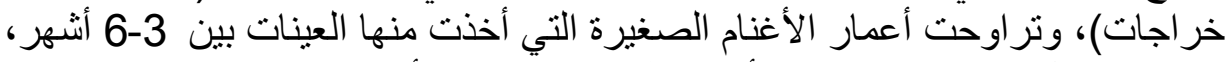

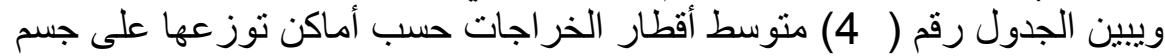

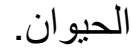


الجدول رقم (4): نقدير حجم الخراج بحساب القطر

\begin{tabular}{|c|c|c|}
\hline مدى قطر الذراج / سم & متوسط قطر الذراج / سم & موقع الذراج \\
\hline $20-2$ & 3 & الد رأس و الثلث الاعلى من الرقبة \\
\hline $20-4$ & 7 & القص و الكتق * \\
\hline $6-3$ & 3,7 & بين الفخذين و بين الظلفين \\
\hline
\end{tabular}

من الصعب تمييز وجود هذه الذراجات وذلك بسبب الصدوف حيث تلاحظ اثثاء وبعد الجز أو

$$
\text { في حال وجود إعاقة في حركة الحيوان أو كبر حجم الذراج }
$$

كما يوضح الجدول رقم ( 5) صفة القيح ولونه في الخراجات حسب العو امل

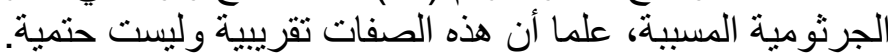

\begin{tabular}{|c|c|}
\hline \multicolumn{2}{|c|}{ الجدول رقم (5): صفات القيح ولونه حسب العامل المسبب } \\
\hline صفة القيح ولونه & 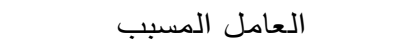 \\
\hline غالبا رائق بلون بني مخضر و رائحة كريهة & Arcanobacterium pyogenes \\
\hline غالبا قوام معجون الاسنان كريمي او اصفر مائل للخضدرة & C. pseudotuberculosis \\
\hline \multirow{2}{*}{ غالبا ما يكون كريمي مصفر } & Staphylococcus \\
\hline & Streptococcus \\
\hline
\end{tabular}

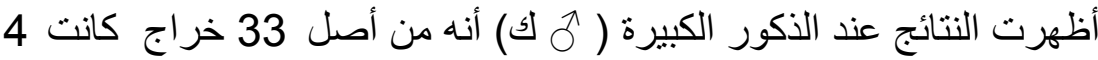

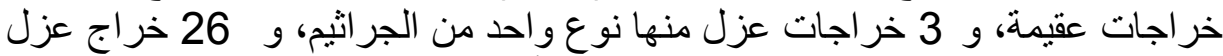

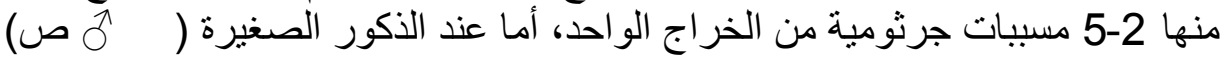

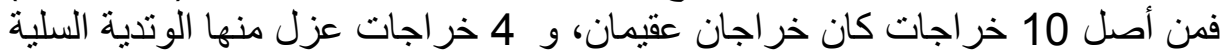

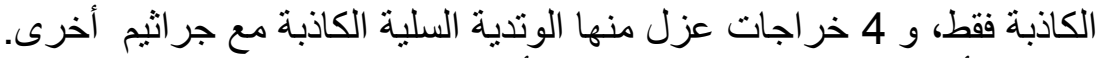

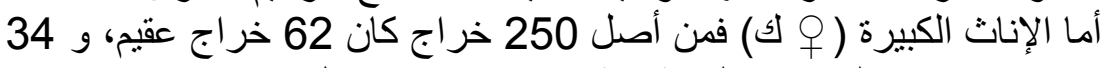

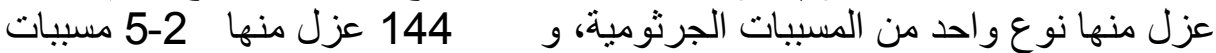

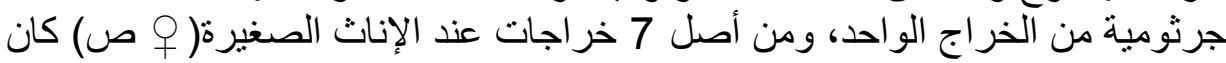

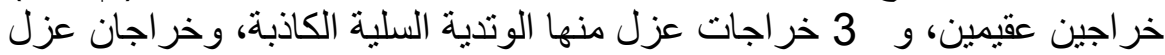

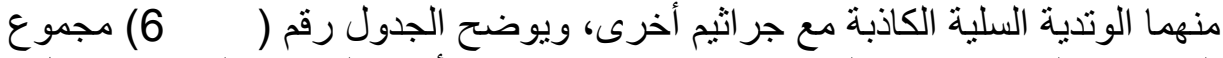
العزو لات الجرثومية من الخراجات عند ذكور و إنات الأغنام الكبيرة و الصغيرة الصغيرة بشكل

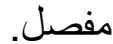


Assiut Vet. Med. J. Vol. 57 No. 130 July 2011

الجدول رقم (6): ذوع وعدد العزولات الجرثومية من الذراجات بشكل مفصل

\begin{tabular}{|c|c|c|c|c|c|c|c|c|}
\hline نسبة عزل & نسبة & النسبة & & ( & لَ & | & ك & \\
\hline 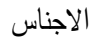 & 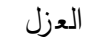 & الكلية & 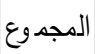 & العدد & العدد & 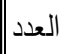 & 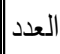 & ذوع المسبب \\
\hline $14 \%$ & $14 \%$ & $8.97 \%$ & 42 & . & . & 32 & 10 & Arcanobacterium pyogenes \\
\hline \multirow{4}{*}{$32 \%$} & $20.33 \%$ & $13.03 \%$ & 61 & 5 & 8 & 43 & 5 & Corynebacterium pseudotuberculosis \\
\hline & $4 \%$ & $2.56 \%$ & 12 & . & . & 11 & 1 & C.ulcerans \\
\hline & $5.33 \%$ & $3.42 \%$ & 16 & . & . & 13 & 3 & C.bovis \\
\hline & $2.33 \%$ & $1.50 \%$ & 7 & . & & 6 & 1 & C.ssp \\
\hline \multirow{4}{*}{$39 \%$} & $9 \%$ & $5.77 \%$ & 27 & . & . & 21 & 6 & Staphylococcus aureus \\
\hline & $15 \%$ & $9.62 \%$ & 45 & 2 & 3 & 31 & 9 & Staphylococcus epidermidis \\
\hline & $9.33 \%$ & $5.98 \%$ & 28 & . & 2 & 20 & 6 & S. heamolyticus \\
\hline & $5.67 \%$ & $3.63 \%$ & 17 & . & . & 12 & 5 & S.lentus \\
\hline $16 \%$ & $16 \%$ & $10.26 \%$ & 48 & . & . & 37 & 11 & Micrococcus \\
\hline \multirow{3}{*}{$15 \%$} & $10 \%$ & $6.41 \%$ & 30 & 1 & 2 & 24 & 3 & Streptococcus pyogenes \\
\hline & $2 \%$ & $1.28 \%$ & 6 & . & . & 6 & . & Str uberis \\
\hline & $3 \%$ & $1.92 \%$ & 9 & . & . & 8 & 1 & Str bovis \\
\hline \multirow{4}{*}{$18 \%$} & $12 \%$ & $7.69 \%$ & 36 & . & . & 27 & 9 & Enterobacter \\
\hline & $3 \%$ & $1.92 \%$ & 9 & . & . & 9 & . & Escherichia coli \\
\hline & $2 \%$ & $1.28 \%$ & 6 & . & & 6 & & Klebsiella \\
\hline & $1 \%$ & $0.64 \%$ & 3 & . & . & 2 & 1 & Pseudomonas species \\
\hline \multirow[t]{2}{*}{$22 \%$} & $22 \%$ & $14.10 \%$ & 66 & . & & 51 & 15 & Bacillus .spp \\
\hline & & $100 \%$ & 468 & 8 & 15 & 359 & 86 & المجموع \\
\hline
\end{tabular}

DISCUSSION

المناقشرة

بينت نتائج هذه الدر اسة و هي الأولى من نوعها في سوريا أن نسبة الأغنام المصابة بالخر اجات السطحية منخفضة بالمقارنة مع عدد الأغنام الكلي للقطعان، وقد 
يعزى هذا إلى دور الغطاء الصوفي الذي يحمي الأغنام من الجروح الحشرات،

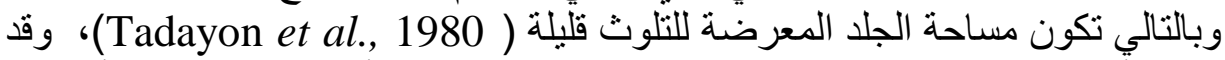

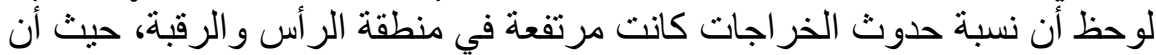

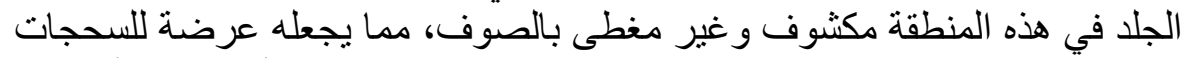

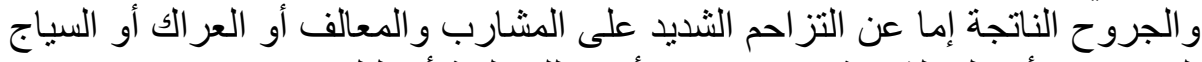

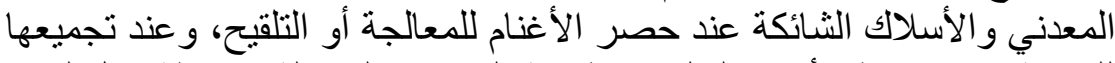

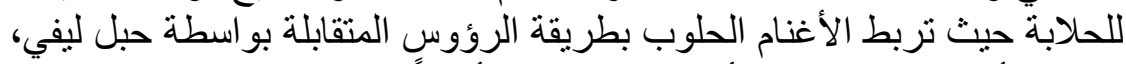

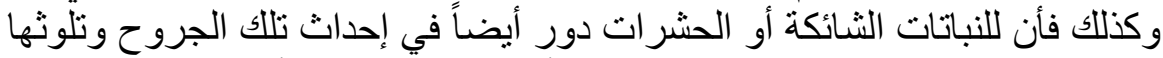

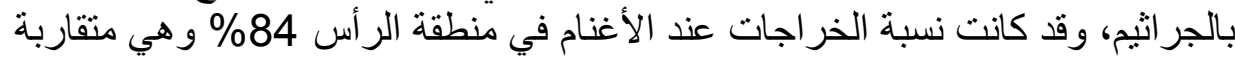

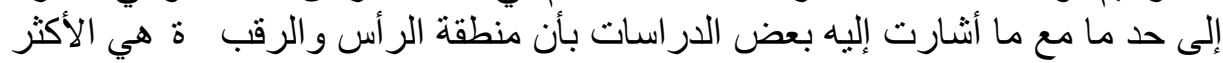

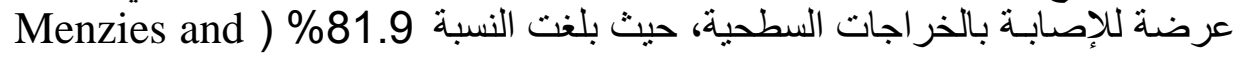

(Muckle, 1989

ومن الجدير بالذكر أن عدد الأغنام الصغيرة المصابة بالخر اجات السطحية

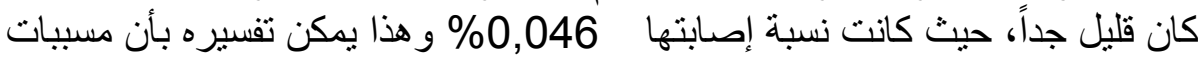

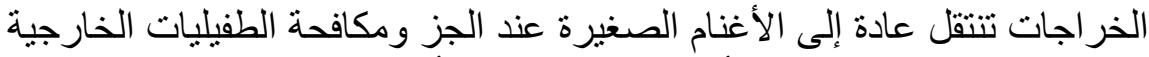

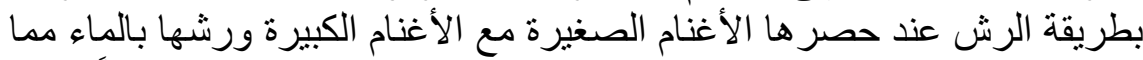

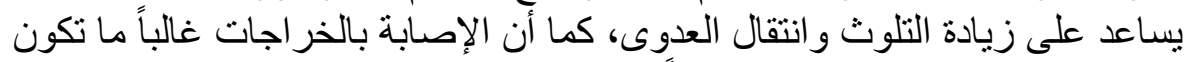

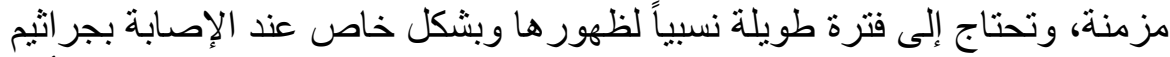

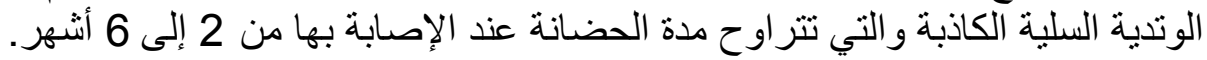

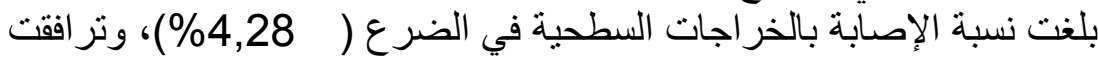

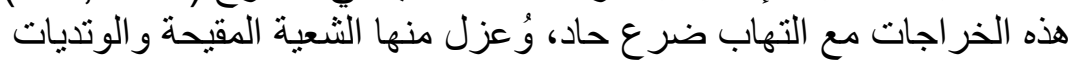
و الإشريكية القولونية و العنقودية الذهبية التهبية.

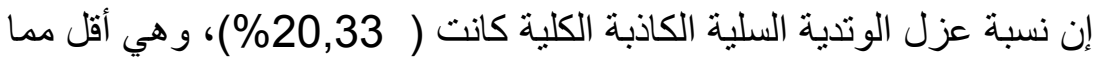

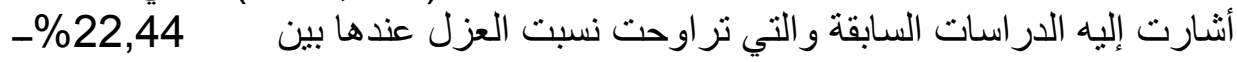
Tadayon et al., 1980; Menzies and Muckle 1989; ) \%32,14

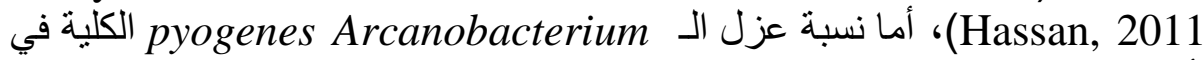

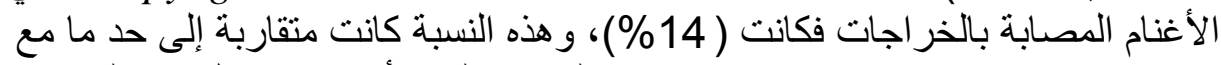

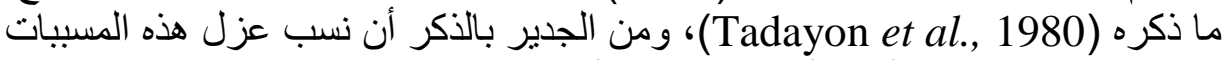

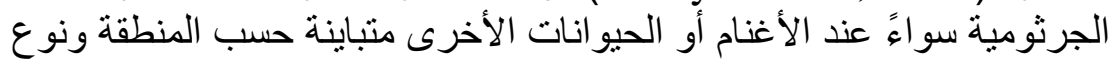

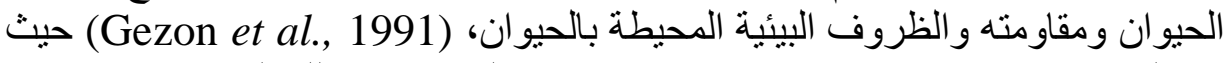

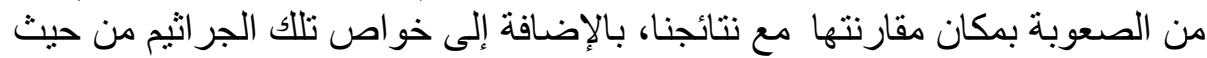

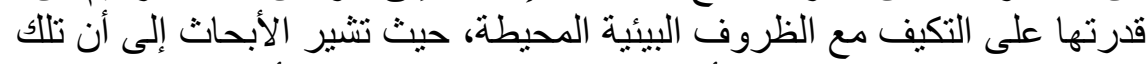

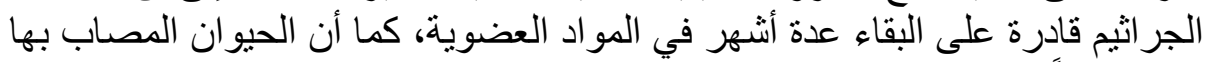
يبقى حاملاً للعدوى مدى الحياة. 
يستنتج من هذا البحث : وجود إصابات بالخراجات السطحية عند الأغنام العواس في

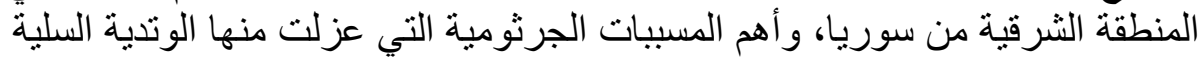

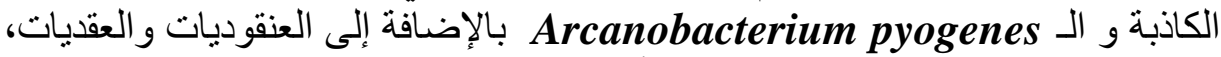

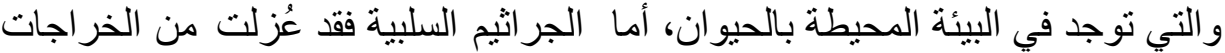

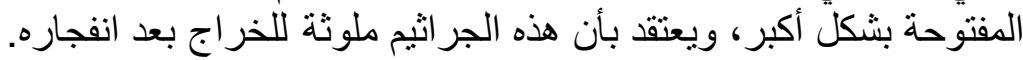

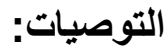

- إز الة الزوايا الحادة الموجودة في المعالف و المشارب وكذلك المحاصر و الأسلاك

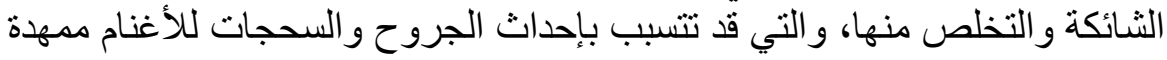
لحدوث الخمج بالخر اجات عبر الجلد.

ـ تعقيم محقن التلقيح ورؤو س الإبر و غير ها من الأدوات التي تستعمل لأكثر من مرة

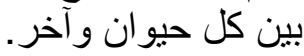

$$
\text { - إتباع الإجر اءات الصحية الوقائية (لتجنب حدوث عدوى بشرية) . }
$$

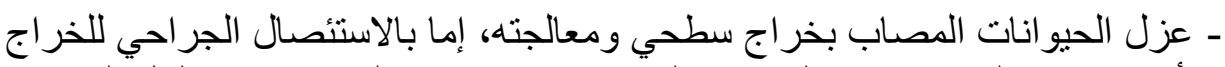

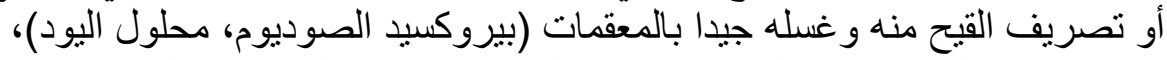

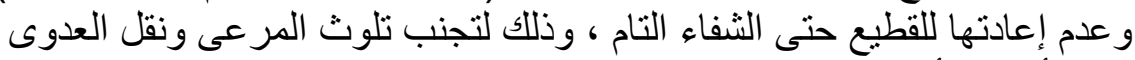

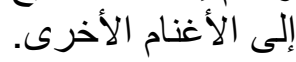

ـ تجنب رعي الأغنام في المناطق التي تكثر بها النباتات الثوكية ما أمكن.

ـ تجنب حصر الحملان الصغيرة مع الأغنام الكبيرة عند التلقيح أو الجز أو مكافحة

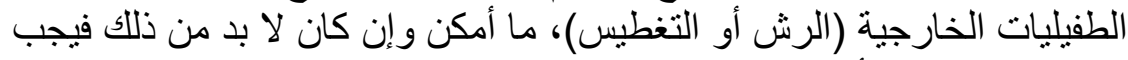
البدء بالحيو انات الأصغر في الرش العمر.

\section{REFERENCES}

Aitken, I.D. (2007): Diseases of the skin, wool and eyes, In;Diseases of Sheep, Blackwell Publishing, $4^{\text {th }}$ ed., p: 297-358.

Babiker, A. and El Sanousi, S. (2004): Effects of Fattening on the Occurrence of Sheep Abscess Disease; Morel's Disease, Deutscher Tropentag, 5-7.

Carter, G.M.; Chengappa, M.M. and Roberts, A.W. (1995): Essentials of Veterinary Microbiology, $5^{\text {th }}$ ed. 
Collins, M.D.; Hutson, R.A.; Hoyles, L.; Falsen, E.; Nikolaitchouk, N. and Foster, G. (2001): Streptococcus ovis sp. nov., isolated from sheep, Inter. J. Systematic and Evolutionary Microbio, 51: 1147-1150.

El Sanousi, S.M.; Hamad, A.A. and Gameel, A.A. (1989): Abscess disease in goats in the Sudan, Elev. Med. Vet. Pays Trop. 42 (3): 379-382.

Ertap, H.B.; Kili, A.; Ozbey, G. and Muz, A. (2005): Isolation of Arcanobacterium (Actinomyces) pyogenes from Abscessed Cattle Kidney and Identification by PCR, Turk J. Vet. Anim. Sci., 29: 455-459.

Gerlach, B.M.; Houser, T.A.; Hollis, L.C.; Tokach, M.D.; Nietfeld, J.C.; Higgins, J.J.; Anderson, G.A. and Goehring, B.L. (1994): Incidence and Severity of Arcanobacterium pyogenes Injection Site Abscesses with Needle or Needle-Free Injection Methods, American J. of Veterinary, 68:270-273.

Gezon, H.M.; Bither, H.D.; Hanson, L.A. and Thompson, J.K. (1991):

Epizootic of external and internal abscesses in a large goat herd over a 16-year period, javma, 198: 257/263.

Gillespie, S.H. and Hawkey, P.M. (2006): Principles and Practice of Clinical Bacteriology, $2^{\text {nd }}$ ed, John Wiley and Sons Ltd, P: 3115. UK.

Glenn, J.S. and Karen, W.P. (2005): Veterinary Microbiology: Bacterial and Fungal Agents of Animal Disease, Elsevier Saunders, $9^{\text {th }}$ ed, P: 10-80. China.

Goldman, E. and Green, L.H. (2009): Practical Handbook of Microbiology, $2^{\text {nd }}$ ed., CRC Press, Taylor and Francis Group, P: 275-374. United States of America.

Gyles, C.L.; Prescott, J.F.; Songer, J.G. and Thoen, C.O. (2004):

Pathogenesis of Bacterial Infections in Animals, Blackwell Publishing, $3^{\text {rd }}$ ed., P:23-86.

Hassan, N.A.; Al Humiany, A.A.; Bahobail, A.S. and Mansour, A.M.A. (2011): Bacteriological and Pathological Studies on Caseous Lymphadenitis in Sheep in Saudi Arabia, Internat. J. of Microbiological Research 2(1): 28-37.

Hirsh, D.C. and Zee, Y.C. (1999): Veterinary Microbiology, Blackwell Science, P: 115-134. 
Jost, B.H. and Billington, S.J. (2005): Arcanobacterium pyogenes: molecular pathogenesis of an animal opportunist, Antonie van Leeuwenhoek, 88: 87-102.

Kanoe, M.; Nouka, K. and Toda, M. (1984): Isolation Of Obligate Anaerobic Bacteria From Bovine Abscesses In Sites Other Than The Liver, J. Med. Microbiol., 18:365/369.

Kusiluka, L. and Kambarage, D. (1996): Diseases Of Small Ruminants in Sub-Saharan Africa, VETAID, P: 24-62.

Lavin, S.; Ruiz-Bascaran, M.; Marco, I.; Abarca, M.L.; Crespo, M.J. and Franch, J. (2004): Foot infections associated with Arcanobacterium pyogenes in free-living Fallow Deer, J. Wildlife Diseases, 40(3): 607-611.

Lloyd, S. (1998): Caseous Lymphadenitis in Sheep and Goats. In; Sheep and Goat Practice 2. Philadelphia: WB Saunders, 185-196.

Mashhadi, A.G.; Poor, M.G. and Soleimani, M. (2006): Bacteriological study of liver abscesses in sheep in Ahvaz of Iran, Pakistan J. ournal of Biological Sciences, 9 (11): 2162-2164.

Menzies, P.I. and Muckle, C.A. (1989): The Use of a Microagglutination Assay for the Detection of Antibodies to Corynebacterium pseudotuberculosis in Naturally Infected Sheep and Goat Flocks, Can. J. Vet. Res., 53: 313-318.

Nagaraja, T.G.; Beharka, A.B.; Chengappa, M.M.; Carroll, L.H.; Raun, A.P.; Laudert, S.B. and Parrott, J.C. (1999): Bacterial Flora of Liver Abscesses in Feedlot Cattle Fed Tylosin or No Tylosin, J. Anim. Sci., 77: 973-978.

North, R. (2004): Goat health;caseous lymphadenitis; cheesy gland, Agfact A7.9.8, second edition, Australia.

Palmer, M.V. and Whipple, D.L. (1999): Arcanobacterium pyogenes as a cause of fatal pleuropneumonia after capture and transport of white-tailed deer, J. Vet. Diagn. Invest., 11: 468-471.

Paton, M. (2005): Cheesy gland in sheep and goats, Replaces Farmnote 30/97,ISSN 0726-934X.

Pedro, N.A. and Szyfres, B. (2001): Zoonoses And Communicable Diseases Common To Man And Animals, In; Bacterial Infections and Mycoses, $3^{\text {rd }}$ ed., Scientific and Technical Publication, P: 191-262.

Quinn, P.J.; Carter, M.E.; Markey, B. and Carter, G.R. (1999): Clincal veterinary microbiology, Mosby, $3^{\text {rd }}$ ed, P: 21-155. 
Tadayon, R.A.; Cheema, A.H. and Muhammed, S.I. (1980): Microorganisms associated with abscesses of sheep and goats in the South of Iran, Am. J. Vet. Res., 41: 798-802.

Walker, B. (1996): Cheesy Gland Caseous Lymphadenitis in Sheep, Agfact A3.9.21, $2^{\text {nd }}$ ed. Australia. 